\title{
Response of an endangered dipterocarp tree species to nutrient addition in a problematic soil
}

\author{
Johannes Reiner G. Asio ${ }^{1 *}$ and Marlito Jose M. Bande
}

\begin{abstract}
The successful establishment of dipterocarp tree species especially in problematic lands is a challenge since it is still poorly understood. The study was conducted to evaluate the effects of the addition of N, P, and K to Yakal-yamban (Shorea falciferoides Foxw.), a critically endangered dipterocarp tree species, grown in a soil derived from an ophiolitic rock. The seedlings were grown in pots inside a screenhouse and then subjected to the following treatments: control, NPK, NP, PK, and NK. Results revealed that NPK addition generally enhanced the growth of Yakal-yamban in the problematic soil, six (6) months after transplanting, particularly in terms of leaf area, biomass increment and allocation in the leaves. The allocation was enhanced in treatments that receive $\mathrm{P}$, in addition to $\mathrm{N}, \mathrm{NK}$, or $\mathrm{K}$ suggesting that $P$ was the most limiting nutrient in the problematic soil used. The study also revealed the occurrence of ectomycorrhiza in Yakal-yamban where $\mathrm{P}$ was not applied. The results imply that NPK addition is a potential nutrient management strategy for the seedling establishment of Yakal-yamban in problematic soils.
\end{abstract}

Keywords: Dipterocarp trees, Yakal-yamban, fertilization, problem soil, ophiolite

\section{INTRODUCTION}

Dipterocarp trees (Dipterocarpaceae) have crucial ecological roles such as in the prevention of landslides, sequestration of atmospheric carbon, and biodiversity conservation. They are also economically important in terms of timber production. However, the successful establishment of dipterocarp trees especially in problematic lands is still a challenge since limited studies have been conducted about it until now. This is particularly so in terms of the ability of these forest trees to thrive in marginal lands like those naturally-contaminated with heavy metals and those with very low nutrient status such as ophiolitic and serpentinite areas

${ }^{1 * 1}$ Institute of Tropical Ecology and Environmental Management, Visayas State University, Baybay City, Leyte, 6521, Philippines

*Corresponding Author. Address: Institute of Tropical Ecology and Environmental Management, Visayas State University, Baybay City, Leyte, 6521, Philippines; Email: johannes.asio@vsu.edu.ph

DOI:10.32945/atr4118.2019 
(Corlett \& Primack 2006, Department of Environment \& Natural Resources [DENR] 2012, Appanah 1998, Walpole 2010).

Dimalanta et al (2006) reported that ophiolite rocks are widespread in Leyte, Samar, Cebu and Palawan. A typical ophiolite complex is a stratified igneous rock complex that consists of different rock layers: an upper igneous rock, a middle gabbro complex, and a lower peridotite complex of ultramafic origin (Dilek 2003). Large areas in the above-mentioned islands which are underlain by ophiolite rocks have marginal soils which are problematic soils for crop production and forest rehabilitation. Although the fertility of soils developed from ophiolite rocks in the Philippines has not yet been studied in detail, studies elsewhere have shown that such soils are generally moderately acidic to neutral, have low soil organic matter, nitrogen $(\mathrm{N})$, phosphorus $(\mathrm{P})$, and potassium $(\mathrm{K})$ status and contain high amounts of heavy metals, such as chromium, nickel, iron, and cobalt among others (D'Amico 2009).

Mineral fertilizers have been used in agriculture and forestry to improve crop yield, biomass production, and soil fertility status. The study hypothesized that the addition of $N, P$, and $K$ to Yakal-yamban (Shorea falciferoides Foxw.) grown in soils derived from ophiolitic rocks will enhance its growth. This dipterocarp species was chosen since it had been known to thrive in the ophiolitic and serpentinite areas of Samar and it is critically endangered, thus the need to preserve this dipterocarp species from becoming extinct (Fernando et al $2009 \& 2008$ ). This is the first study dealing with the mineral nutrition of this endangered dipterocarp tree species.

\section{MATERIALS AND METHODS}

The soil used as potting medium was selected based on the project report of the VSU-OXFAM Project (2015). Detailed soil analysis done by the project showed that the soils in Padang, Hernani, Eastern Samar developed from ophiolitic rocks and have low levels of N, P, K, and Mg, but high levels of $\mathrm{Ca}$. Twenty sacks of topsoil ( 0 $30 \mathrm{~cm}$ depth) were collected and transported to the Terrestrial Ecosystems Division of the Institute of Tropical Ecology and Environmental Management, Visayas State University, Baybay City, Leyte. The bulk soil samples were mixed, air-dried thoroughly, pulverized, and sieved using a $4 \mathrm{~mm}$ mesh sieve. About $1.5 \mathrm{~kg}$ of the airdried soil, $0.75 \mathrm{~kg}$ sieved soil (from the $4 \mathrm{~mm}$ sieve), and $0.75 \mathrm{~kg}$ unsieved soil WERE weighed and placed in each polyethelene bag $(10 \times 10 \times 25 \mathrm{~cm})$ to avoid soil compaction.

This pot experiment was conducted in a screen house using a $5 \times 3$ Randomized Complete Block Design (RCBD) with five treatments and three replicates, wherein each treatment per replication consisted of 10 seedlings (Figure 1). The seedlings were applied with single-element fertilizers at transplanting time following the recommended rate by Bungard et al (2002) on per plant basis. The treatments were as follows: $\mathrm{T}_{1}$-Control (No fertilizer application), $\mathrm{T}_{2}$-NPK (Application of $3.65 \mathrm{~g}$ of Urea, $9.33 \mathrm{~g}$ of Solophos, \& $2.8 \mathrm{~g}$ of Muriate of Potash), $\mathrm{T}_{3}-\mathrm{NP}$ (Application of $3.65 \mathrm{~g}$ of Urea, $9.33 \mathrm{~g}$ of Solophos), $\mathrm{T}_{4}-\mathrm{PK}$ (Application $9.33 \mathrm{~g}$ of Solophos \& $2.8 \mathrm{~g}$ of Muriate of Potash), $\mathrm{T}_{5}$-NK (Application of $3.65 \mathrm{~g}$ of Urea \& $2.8 \mathrm{~g}$ of Muriate of Potash). Placement application was done wherein the exact amount of fertilizer for each seedling was applied a few centimeters below the soil surface. Tap water was used in watering the plants. About $400 \mathrm{~mL}$ (based on the field capacity of the soil) was added as required. 

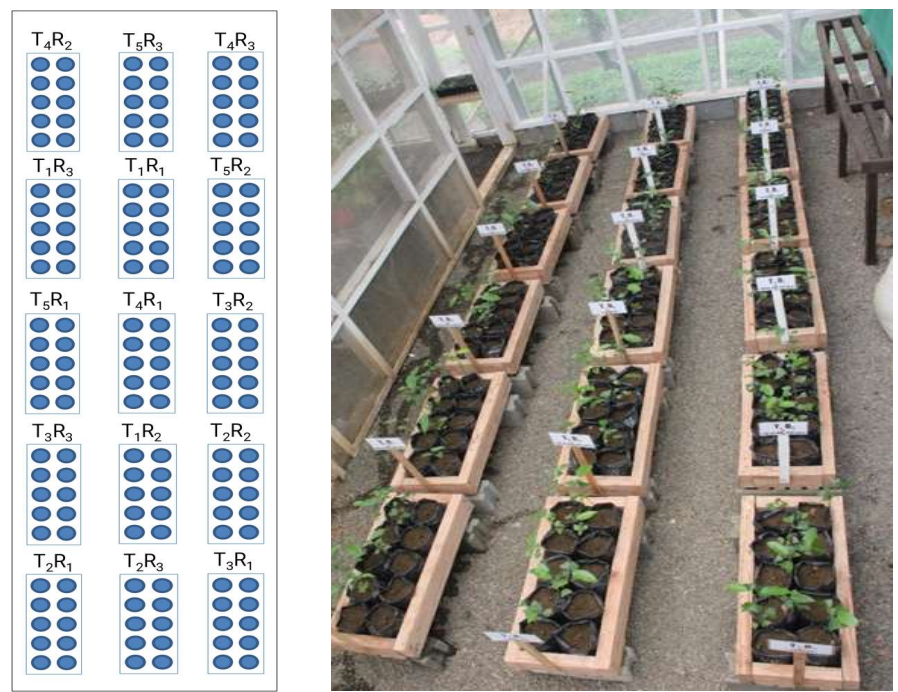

Figure 1. Lay-out of the pot experiment

Three (3) randomly selected seedlings in each replication were harvested after 3 months and 6 months from transplanting. The selected seedlings were photographed, documenting each plant part and making notable observations. Thereafter, each individual seedling was cut; each leaf was photographed in preparation for leaf area analysis. Then, each plant part (roots, stem, \& leaves) was separated and placed into the corresponding paper bags ready for oven drying. The soil samples in each replication were mixed and placed in labelled plastic bags ready for air-drying and analysis following standard procedures.

This study focused on three (3) morphological traits (eg, total height increment, root-collar diameter increment, and leaf area) and three (3) physiological traits (eg, growth biomass increment, biomass allocation, \& root-shoot ratio). The optimum nutrient combination for Yakal -yamban seedling quality was evaluated based on the root-shoot ratio; the leaf area was read using the Leaf Area Calculator developed by the Department of Computer Science, Visayas State University, Baybay City, Leyte. Soil and plant analyses were done following the methods of ISRIC (2002), Schlichting et al (1995), and Westerman (1990). All data were tested for normality and homogeneity using PROC Univariate of Statistical Analysis System version 9.1. Duncan multiple range test (DMRT) and least square differences (LSD) were carried out to compare treatment means of independent variables at $5 \%$ level of significance $(p<0.05)$.

\section{RESULTS \& DISCUSSION}

\section{Morphological Parameters}

Results revealed no significant differences in the total height increment and rootcollar diameter increment of Yakal-yamban 3 months after transplanting (3 MAT) (Figure 2). However, it can be observed that the effects of the treatments improved at 6 MAT. This indicates that the nutrient requirement of the trees increased with age and is the reason why the sample plants have already appeared to respond to nutrient addition. 
Response of an endangered dipterocarp tree species
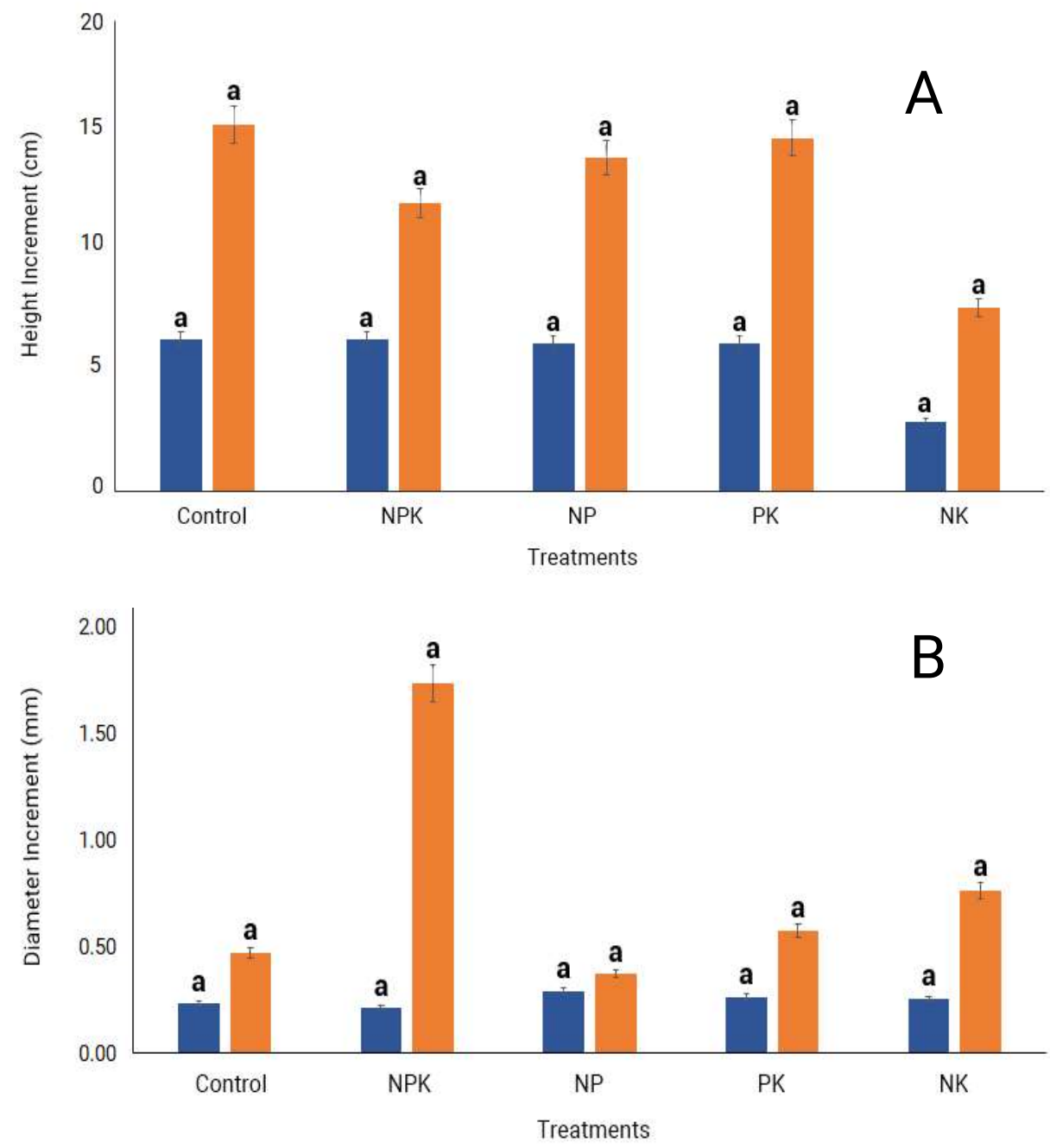

Figure 2. Total height increment (A), total root-collar diameter increment (B) of Yakal-yamban at 3 months after transplanting (3MAT) and 6 MAT. (Note: different letter superscripts among treatments in the same harvesting period are significantly different at $p \leq 0.05, n=9$. Error bars are in percentage)

Figure 3 reveals that leaf area of the Yakal-yamban seedlings was not significantly affected by nutrient addition at 3 MAT, but significant differences were observed $(p<0.01)$ at 6 MAT with the NPK and PK treatments registering the highest leaf area value. It has been proven in various studies that nitrogen enhances the leaf morphology of a plant (Marschner 1995, Kandil 2013, Amin 2011, Chen et al 2013, El-Noemani et al 1990). However, results revealed that treatments with $P$ application gave the highest leaf area. This indicates that $P$ is probably the most critical nutrient in the soil. It may also imply that Yakal-yamban is sensitive to $P$ levels in the soil. According to Freeden et al (1989) and Marschner (1995), P can enhance the morphology of leaves (eg, expansion \& quantity produced). 


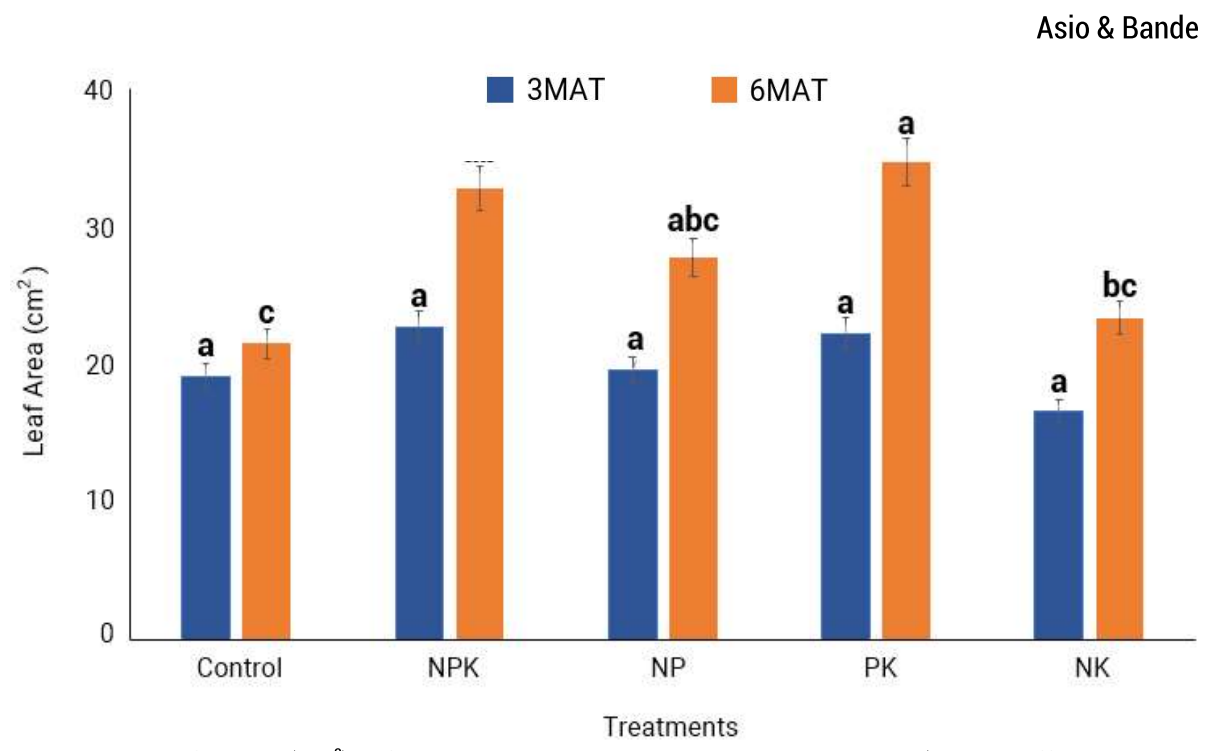

Figure 3. Leaf area $\left(\mathrm{cm}^{2}\right)$ of Yakal-yamban at 3 MAT and 6 MAT (Note: different letter superscripts $(\mathrm{a}-\mathrm{c})$ among treatments in the same harvesting period are significantly different at $p \leq 0.05, n=9$. Error bars are in percentage)

\section{Physiological Parameters}

Results revealed no significant differences between treatments in terms of leaf, stem and leaf biomass increment (Figure 4). The same trend was observed in total height increment, and root-collar diameter increment and is correlated with age as it improved through time. However, in terms of allocation, significant differences were observed between treatments in the root, stem, and leaves, with treatment 5 showing the highest allocation in the roots.

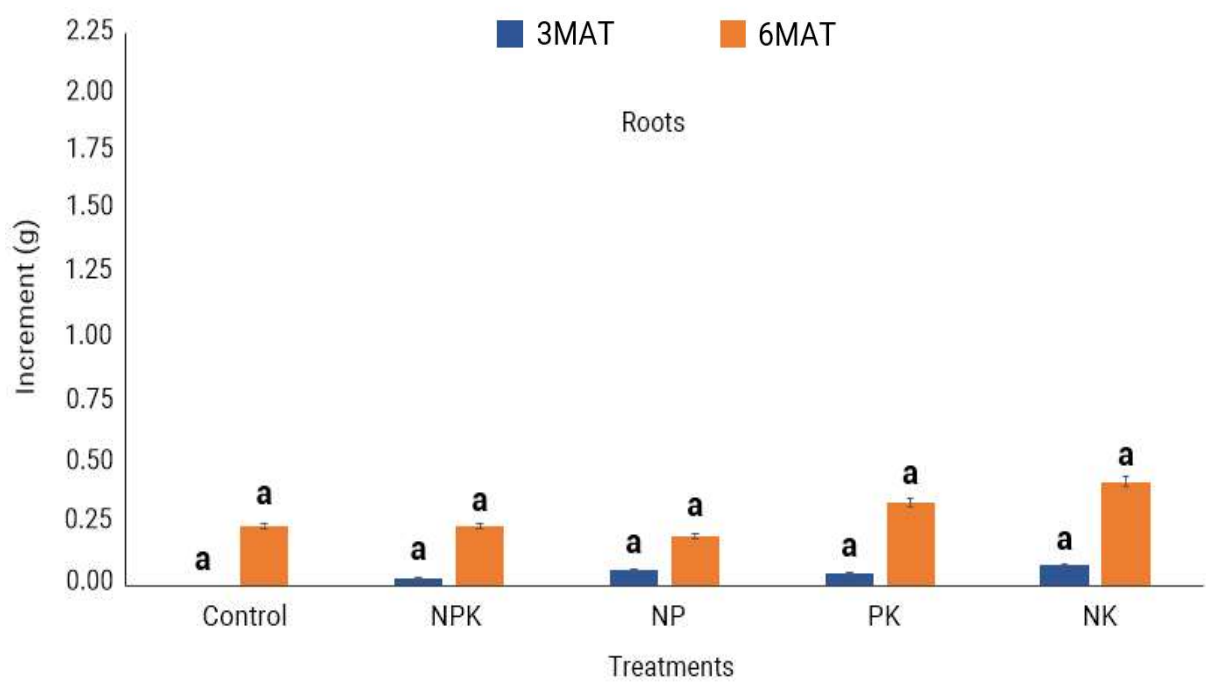

Figure 4. Root, stem, and leaf biomass increment (g) of Yakal-yamban 3 MAT and 6 MAT (Note: different letter superscripts of the same harvesting period among treatments are significantly different at $p \leq 0.05, \mathrm{n}=9$. Error bars are in percentage) 
Response of an endangered dipterocarp tree species
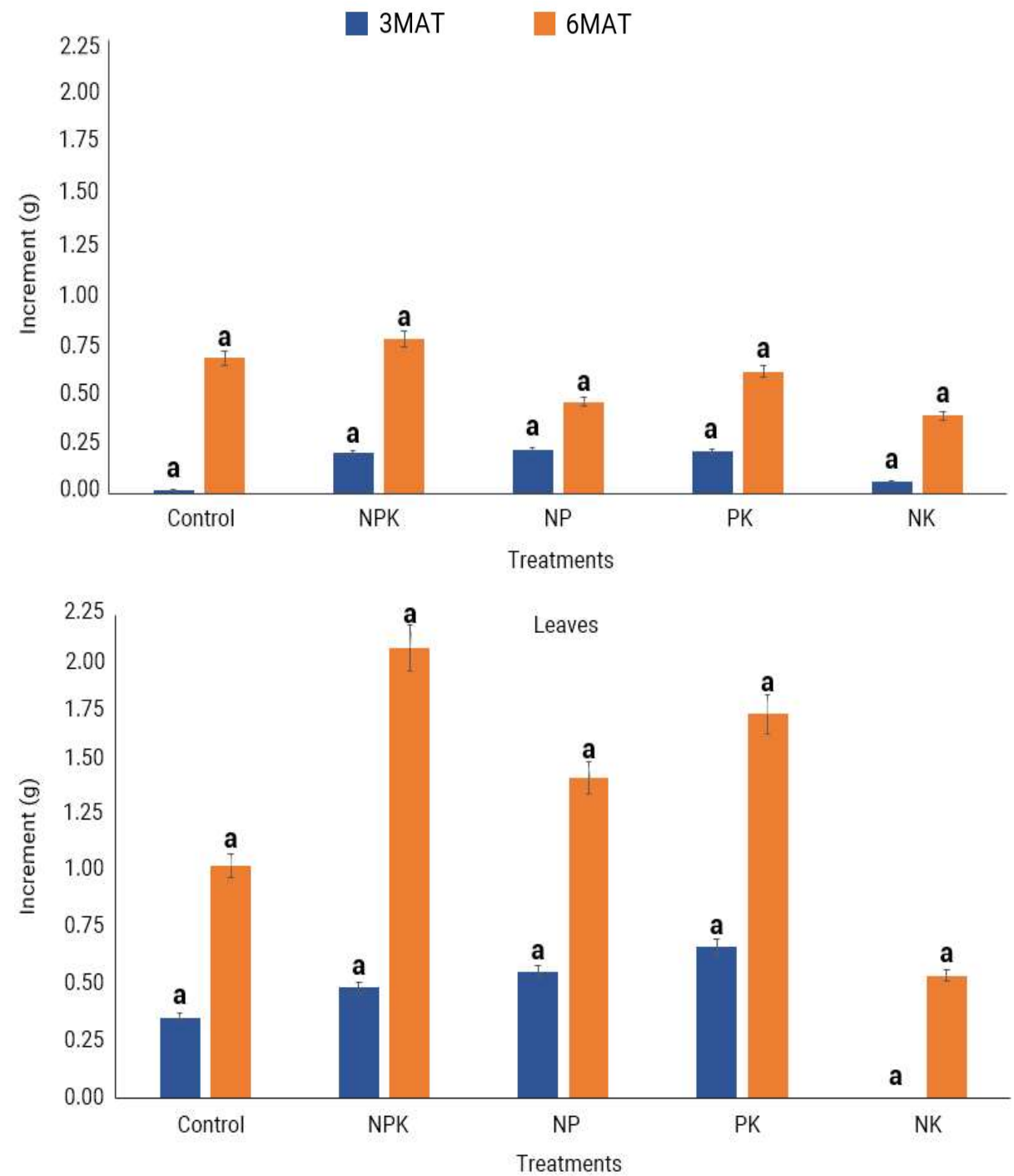

Figure 4. Continuation

Figure 5 reveals that biomass allocations to the roots, stems, and leaves were not significantly different at 3 MAT except in plants added with NK which registered the lowest allocation to the leaves. This finding suggests that the plants were not yet generally affected by the low soil fertility probably because their nutrient requirement was still low. Results also revealed that biomass allocation to the leaves increased at 6 MAT compared to that at 3 MAT. In addition, the allocation to the leaves was significantly higher in plants that received NPK, NP and PK implying that the $\mathrm{P}$ addition was the one that caused the increase in the biomass allocation. Freeden et al (1989) and Camacho et al (2002) observed that P deficiency could lead to the reduction in the leaf morphology specifically in the number of leaves among others. 


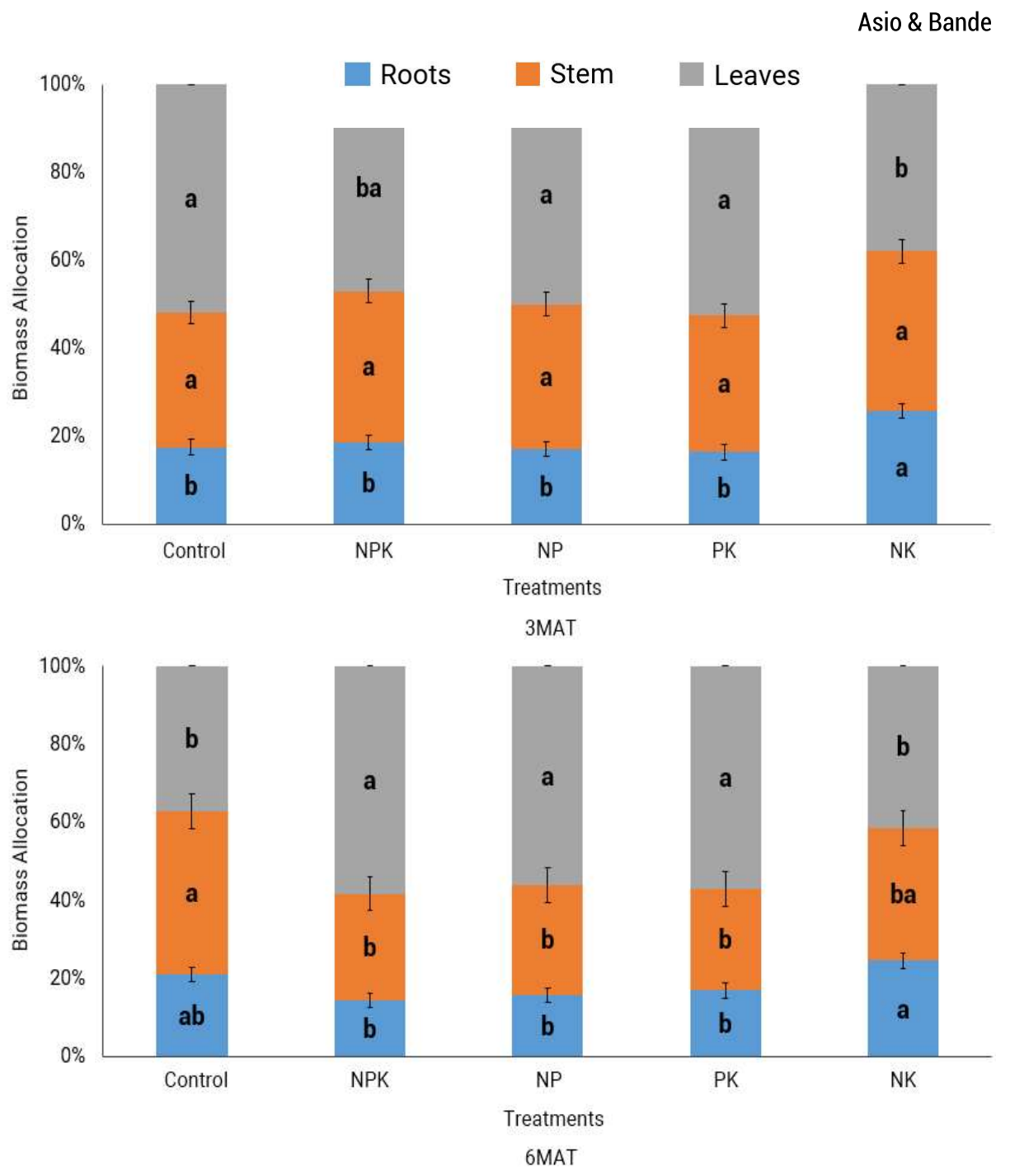

Figure 5. Percent biomass allocation of Yakal-yamban at 3 MAT and 6 MAT (Note: different letter superscripts $(a-b)$ of the same harvesting period among treatments are significantly different at $p \leq$ $0.05, n=9$. Error bars are in percentage)

Figure 6 shows that the NK treatment exhibited the highest root-shoot ratio among the treatments both at 3 MAT and 6 MAT. Plants in P-deficient environments are known to enhance their root growth as it is their adaptive mechanism that enables them to thrive in these conditions. This in turn may also serve as a nutrient deficiency symptom for plants growing in P-poor conditions (Schulze et al 2005, Freeden et al 2005) and may imply that P levels in the soil is very critical for the growth of Yakal-yamban. 
Response of an endangered dipterocarp tree species

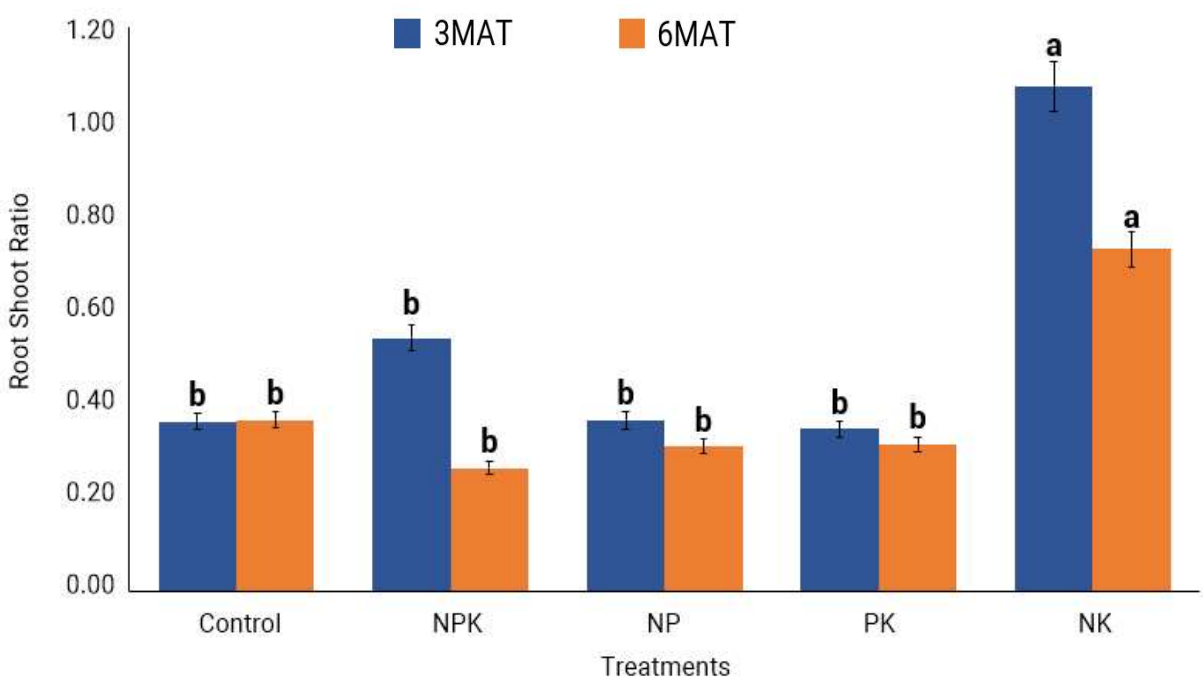

Figure 6. Root-shoot ratio of Yakal-yamban 3 MAT and 6 MAT. (Note: different letter superscripts (ab) of the same harvesting period among treatments are significantly different at $p \leq 0.05, n=9$. Error bars are in percentage)

\section{Other Observations}

The presence of ectomycorrhizae (EcM) was also observed in the roots of Yakal-yamban trees in the control and NK treatment. This shows that EcM developed in the roots of the experimental plants that did not receive any $P$ fertilizer as an adaptation mechanism to $P$ deficiency in the soil. Various studies have proven that mycorrhiza aids in the growth of a plant as it enhances the absorption of nutrients particularly $P$ and water (Marschner 1995, Read 1991). The result also agrees with the study of Turner et al (1992) that EcM infection may serve as a purpose when dipterocarps are grown in nutrient-poor conditions (Figure 7). As far as we know, this is the first scientific evidence for the ectomycorrhiza occurrence in Yakal-yamban.

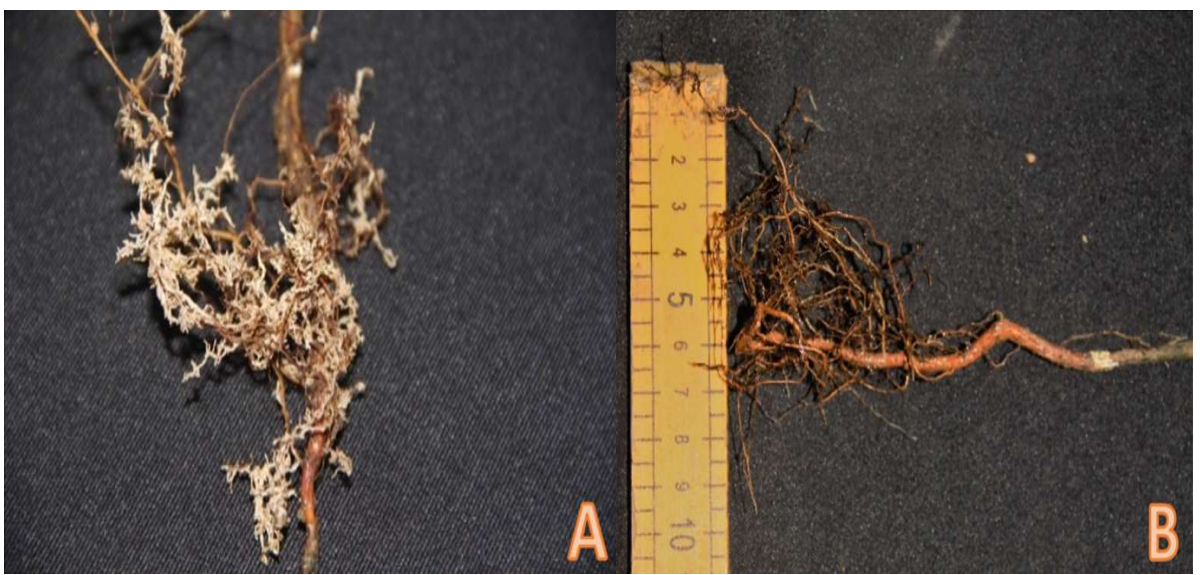

Figure 7. Ectomycorrhizal infection in the roots of the Yakal-yamban plants that received no nutrient (control)(A) as compared to the roots of plants applied with NPK (B) at 6MAT 


\section{CONCLUSIONS}

NPK addition generally enhanced the growth of Yakal-yamban in the problematic soil six (6) months after transplanting particularly in terms of leaf area, biomass increment and allocation to the leaves. The allocation was enhanced in treatments that received $\mathrm{P}$ in addition to $\mathrm{N}$, NK, or $\mathrm{K}$ suggesting that $\mathrm{P}$ was the most limiting nutrient in the problematic soil used. The study also revealed the occurrence of ectomychorrizha in Yakal-yamban where $\mathrm{P}$ was not applied. The results imply that NPK addition is a potential nutrient management strategy for the seedling establishment of Yakal-yamban in problematic soils.

\section{REFERENCES}

Amin ME-M. 2011. Effect of different nitrogen sources on growth, yield, and quality of fodder maize (Zea mays L.). Journal of the Saudi Society of Agricultural Sciences 10(1):17-23

Appanah S and Turnbull JM. 1998. Introduction. In Appanah S, Ashton MS, Bawa KS, Krishnapillay B, Lee SS, Maurey-Lechon G and G. Weinland (eds) A Review of Dipterocarps: Taxonomy, Ecology, and Silviculture (pp220). Center for International Forestry Research, Bogor, Indonesia

Bungard RA, Zipperlin SA, Press MC \& Scholes JD. 2002. The influence of nutrients on growth and photosynthesis of seedlings of two rainforest dipterocarp species. Functional Plant Biology 29(4):505-515

Camacho R, Malavolta E, Guerrero-Alves J \& Camacho T. 2002. Vegetative growth of grain sorghum in response to phosphorus nutrition. Scientia Agricola 59(4):771-776

Chen J, Zhu R \& Zhang Y. 2013. The effect of nitrogen addition on seed yield and yield components of Leymus chinensis in Songnen Plain, China. Journal of Soil Science and Plant Nutrition 13(2):329-339

Corlett R and Primack R. 2006. Dipterocarps: Trees that dominate the Asian rain forest. Arnoldia 63(3):2-7

D' Amico ME. 2009. Soil ecology and pedogenesis on ophiolitic materials in the western alps (Mont Avic Natural Park, Northwestern Italy): Soil Properties and their Relationships with Substrate, Vegetation, and Biological activity (pp122). Dottorato di ricerca in Scienze Ambientali, Università degli Studi di Milano Bicocca

Department of Environment and Natural Resources, Ecosystems Research and Development Bureau. 2012. Country report on forest genetic resources. Laguna, Philippines: Lobster Printing

Dilek Y. 2003. Ophiolite concept and its evolution. Special Paper of the Geological Society of America (pp1-16)

El-Noemani A, Abd-El-Halim AK \& El-Zeiny HA. 1990. Response of maize (Zea mays L.) To Irrigation Intervals under Different Levels of Nitrogen Fertilization. Egyptian Journal of Agronomy 15(1-2):147-158. Retrieved March 25, 2017 from https://www.cabdirect.org/cabdirect/abstract/19920750461

Fernando ES. 2008. Forest Formations in the Philippines. Korea, Seoul: ASEANKorea Environmental Cooperation Unit 
Response of an endangered dipterocarp tree species

Fernando ES, Bande MJ, Ceniza MJ, Dolotina NE, Granert WG, Milan PP \& Sopot DD. 2009. Habitats of Philippine Dipterocarps. Soil and Water Conservation Foundation

Freeden AL, Madhusudana Rao I \& Terry N. 1989. Influence of phosphorus nutrition on growth and carbon partitioning in glycine max. Plant Physiology 8(1):225230

ISRIC (International Soil Reference Information). 2002. In van Reeuwijk LP (ed) Procedure for Soil Analysis (6th edn). Food and Agriculture Organization of the United Nation. Wageningen, The Netherlands

Kandil E. 2013. Response of some maize hybrids (Zea mays L.) to different levels of nitrogenous fertilization. Journal of Applied Sciences Research 9(3):19021908

Marschner H. 1995. Mineral Nutrition of Higher Plants (2nd edn). Academic press Inc. San Diego, California

Read D. 1991. Mycorrhizas in Ecosystems. Experientia 47(4):376-390

Schlichting E, Blume H \& Stahr K. 1995. Bodenkundliches Praktikum 2 (pp295). Auflage

Schulze E-D, Beck E \& Müller-Hohenstein K. 2005. Plant Ecology. Berlin: Springer

Turner IM, Brown ND \& Newton AC. 1993. The effect of fertilizer on dipterocarp seedling growth and mycorrhizal infection. Forest Ecology and Management 57(1-4):329-337

VSU-OXFAM. 2015. Establishment of Techno-Demo on Crop Diversification Scheme as Learning Farms and Enhancement of Coco-based Production Systems Through Intercropping. Baybay City, Leyte

Walpole P. 2010. Figuring the Forest Figures; Understanding Forest Cover Data in the Philippines and where we might be proceeding. Philippines: Environmental Science for Social Change

Westerman RL. 1990. Soil Testing and Plant Analysis. Madison, Wisconsin, USA: Soil Science Society of America, Inc 